PENELITIAN

\title{
Perbandingan Pemberian Deksametason Intravena dan Lidokain Spray pada Kejadian Nyeri Tenggorok Paska Ekstubasi
}

\section{Comparison of Applied Intravenous Dexamethasone and Lidocaine Spray with Incidence of Sore Throat Post Endotracheal Extubation}

\author{
Chandra Tirta Setiawan Achmad $\triangle^{*}$, Doso Sutiyono* \\ * RS Syarif Hidayatullah, Ciputat, Tangerang Selatan \\ *Bagian Anestesi dan Terapi Intensif FK UNDIP/ RSUP Dr. Kariadi \\ $\triangle$ Korespondensi/Correspondence: guedinaz@gmail.com
}

\begin{abstract}
Background: Sore throat is one of the most common complications following endotracheal intubation, occurring in $30-70 \%$ of patients after endotracheal intubation. This is caused by inflammation of the mucosa of the trachea. Dexamethasone and lidocaine are believed to suppress the inflammation process in post-tracheal intubation.
\end{abstract}

Objective: To determine the effectiveness of iv dexamethasone in preventing sore throat compared with lidocaine spray

Methods: A randomized double-blind clinical trial. The research sample 58 people were divided into 2 groups. Group 1 (Kl) is given dexametasone iv $10 \mathrm{mg}$ before intubation, group 2 (K2) is given lidocaine spray on the endotracheal tube length of 15 $\mathrm{cm}$ from the distal end. The quality of sore throat is being assessed at the 1st, 6th and 24th hour post-extubation.

Results: There is no significant differences in the incidence of sore throat in both groups a the 1st, 6th and 24th hour $(p=0.078, p=1.0, p=1.0)$. There is no significant difference in the incidence of hoarseness in both groups at the 1st, 6th and 24 th hour $(p=0.091, p=1.0, p=1.0)$

Conclusion: Applied dexamethasone IV pre-induction to prevent sore throat in patients undergo general anesthesia with endotracheal intubation is no more effective than lidocaine spray. Keywords: Sore throat, Dexamethasone IV, Lidocaine spray, endotracheal intubation.

Key Word: Sore Throat, Deksametason i.v, Lidokain spray, endotrakhea intubation.

\section{ABSTRAK}

Latar Belakang: Nyeri tenggorok merupakan salah satu komplikasi paska intubasi endotrakeal tersering, terjadi pada 30-70\% pasien paska intubasi endotracheal. Hal ini disebabkan karena inflamasi dari mukosa trakea. Deksametason dan lidokain dipercaya bisa menekan inflarnasi pada mukosa trakea paska intubasi endotrakhea.

Tujuan: Mengetahui efektivitas deksametason iv untuk mencegah nyeri tenggorok dibandingkan dengan lidokain spray.

Metode: Penelitian jenis uji klinis acak tersamar ganda. Sampel penelitian 58 orang dibagi menjadi 2 kelompok. Kelompok 1 (Kl) diberikan dexametasone i.v $10 \mathrm{mg}$ 
sebelum intubasi, kelompok 2 (K2) diberikan spray lidokain pada pipa endotrakea sepanjang $15 \mathrm{~cm}$ dari ujung distal. Kejadian nyeri tenggorok dinilai pada jam ke-1, ke-6 dan ke-24 paska ekstubasi.

Hasil: Terdapat perbedaan tidak bermakna kejadian nyeri tenggorok pada kedua kelompok pada jam ke-1, ke-6 dan ke-24 ( $p=0,078, p=l, 0, p=l, 0)$. Terdapat perbedaan tidak bermakna kejadian suara serak pada kedua kelompok pada jam ke-1, ke-6 dan ke-24 $(p=0,091, p=l, 0, \boldsymbol{p}=l, 0)$

Simpulan: Pemberian deksametason i.v pre induksi untuk mencegah nyeri tenggorok pada pasien anestesi umum dengan intubasi endotrakhea tidak lebih efektif dibandingkan dengan lidokain spray.

Kata Kunci: Nyeri tenggorok, Deksametason i.v, Lidokain spray, intubasi endotrakhea.

\section{PENDAHULUAN}

Nyeri tenggorokan setelah operasi merupakan salah satu komplikasi yang tersering setelah intubasi endotrakeal, yakni terjadi $30 \%$ hingga $70 \%{ }^{1}$ Nyeri tenggorokan sangat tidak nyaman bagi pasien selain nyeri akibat pembedahannya sendiri. Terjadi akibat iritasi lokal dan inflamasi pada jalan napas. Nyeri tenggorokan setelah operasi sulit dikontrol, meskipun nyeri operasi telah sukses diatasi dengan pemberian analgetik sistemik, seringkali terjadi akibat iritasi pada jalan napas akibat pemasangan pipa endotrakeal sehingga merangsang terjadinya batuk dan suara serak. Oleh karena itu, pencegahan nyeri tenggorok merupakan masalah yang penting.

Kejadian nyeri tenggorok tergantung pada beberapa faktor seperti trauma mukosa laring akibat laringoskopi, pemasangan pipa lambung, seringnya melakukan suctioning, ukuran pipa endotrakeal tube (ETT), tekanan cuff ETT, bentuk cuff ETT, luas cuff ETT yang kontak dengan trakea, tekanan pada perfusi kapiler mukosa laring, pergerakan, lamanya dan manipuiasi saat melakukan intubasi, usia, dan jenis kelamin ${ }^{2}$.

Walaupun gejalanya menghilang secara spontan tanpa terapi, manajemen profilaksis untuk mengurangi frekuensi dan beratnya nyeri tenggorok masih direkomendasikan untuk meningkatkan kualitas perawatan setelah anestesi. Beberapa metode farmakologis yang telah disarankan untuk mengurangi nyeri tenggorok setelah operasi termasuk pemberian obatobatan pencegahan yang diberikan sebelum intubasi, pemakaian lubrikasi pada ETT, pemakaian anestesi lokal spray, menggunakan anestesi lokal untuk pengisian cuff pipa ETT, atau berkumur dengan azulene sulfonate.

Steroid diketahui sebagai agen antiinflamasi. Penelitian sebelumnya telah menjelaskan efek pemberian steroid secara lokal untuk mengurangi nyeri tenggorokan setelah intubasi trakea. Park SH dkk telah meneliti profilaksis deksametason bermanfaat untuk mengatasi nyeri paska intubasi menggunakan Double-Lumen. ${ }^{3}$ Penelitian Tabari dkk 
tentang efektifitas betametason jelly dibandingkan deksametason IV, didapatkan hasil bahwa betametason jelly lebih efektif mengatasi nyeri tenggorok paska ektubasi. ${ }^{4}$ Sedangkan Honma dkk telah membuktikan efektifitas spray lidokain yang diberikan 10 menit sebelum intubasi pada trakea berhasil mengurangi kejadian nyeri tenggorok paska intubasi. ${ }^{5}$ Sumathi dkk mendapatkan angka nyeri tenggorok pada kelompok pipa endotrakeal yang diolesi kortikosteroid lebih rendah dibanding kelompok yang diolesi gel lidokain maupun kelompok kontrol, perbedaan ini bermakna baik pada satu jam, enam jam, dan dua puluh empat jam paska anestesi. ${ }^{6}$

Efek samping sistemik kortikosteroid tergantung dari potensi, absorbsi, dan dosis. Meskipun dosis tunggal deksametason relatif aman, pemberian jangka panjang kortikosteroid berhubungan dengan efek samping yang tidak diinginkan, seperti intoleransi glukosa, mudah infeksi, keterlambatan penyembuhan luka, supresi adrenal, dan avascular necrosis joints.

Pencegahan nyeri tenggorok paska intubasi diminimalisir dengan pemberian anestesi lokal maupun steroid baik secara spray, gel maupun intravena. Penelitian-penelitian sebelumnya, dikatakan bahwa deksametason intravena dan spray lidokain efektif mencegah nyeri tenggorok setelah intubasi endotrakea, namun belum ada penelitian yang membandingkan kedua obat tersebut untuk mengetahui mana yang lebih efektif. Oleh karena itu kami melakukan penelitian yang membandingkan antara deksametason intravena dengan spray lidokain untuk mengetahui obat yang lebih efektif ekstubasi pada anestesi umum.

\section{METODE}

Penelitian ini merupakan uji klinis acak tersamar ganda. Dalam rancangan eksperimental, pengukuran dan observasi dilakukan diawal dan setelah perlakuan.

Pasien yang menjalani operasi elektif dengan anestesi umum di Instalasi Bedah Sentral RSUP Dr. Kariadi Semarang yang memenuhi kriteria inklusi dan eksklusi, kemudian dilakukan consecutive sampling dibagi menjadi dua kelompok berdasarkan tabel acak yang sudah dibuat. Peneliti tidak mengetahui pasien berikutnya (double blind) karena urutan pasien berdasarkan pendaftaran di loket Instalasi Bedah Sentral yang berubah setiap harinya. Kedua kelompok penelitian ini diberi perlakuan yang berbeda sebagai berikut: Kelompok 1 (K1) : diberikan deksametason intravena 10 mg Kelompok 2 (K2) : diberikan spray lidokain pada pipa endotrakea.

\section{HASIL}

Sebanyak 58 orang pasien yang menjalani operasi dengan anestesi umum yang dibagi menjadi 2 kelompok, yaitu kelompok $\mathrm{Kl}$ pasien untuk kelompok yang diberikan deksametason intravena 
Tabel 1. Perbedaan rerata \pm simpang baku usia, BB, TB dan lama operasi antara kelompok Dexametason iv dan spray Lidokain

\begin{tabular}{lcc}
\hline \multirow{2}{*}{ Kelompok } & \multicolumn{2}{c}{ Rerata \pm SB } \\
\cline { 2 - 3 } & Dexametason iv & Lidokain spray \\
\hline Usia & $41,24 \pm 11,294$ & $42,48 \pm 13,558$ \\
BB & $58,31 \pm 9,146$ & $60,55 \pm 10,280$ \\
TB & $161,79 \pm 7,537$ & $1-63,14 \pm 7,254$ \\
Lama operasi & $139,66 \pm 28,092$ & $127,93 \pm 28,956$ \\
\hline
\end{tabular}

Keterangan : Independent t-test: Mann Whitney test

Tabel 2. Tabel perbandingan skala nyeri tenggorok pada kedua kelompok perlakuan jam ke 1, 6 dan 24.

\begin{tabular}{ccccccccc}
\hline & \multicolumn{2}{c}{ Skak 10} & Skala 1 & \multicolumn{2}{c}{ Skala 2 } & \multicolumn{2}{c}{ Skala 3 } \\
\cline { 2 - 9 } & K1 & K2 & K1 & K2 & K1 & K2 & K1 & K2 \\
\hline Jam ke-1 & 29 & 26 & 0 & 3 & 0 & 0 & 0 & 0 \\
\hline Jam ke-6 & 29 & 29 & 0 & 0 & 0 & 0 & 0 & 0 \\
\hline Jam ke-24 & 29 & 29 & 0 & 0 & 0 & 0 & 0 & 0
\end{tabular}

Tabel 3. Tabel perbandingan suara serak pada kedua kelompok perlakuan jam ke 1,6 dan 24

\begin{tabular}{ccccccccc}
\hline & \multicolumn{2}{c}{ Skala 0 } & \multicolumn{2}{c}{ Skala 1 } & \multicolumn{2}{c}{ Skala 2 } & \multicolumn{2}{c}{ Skala 3 } \\
\cline { 2 - 10 } & K1 & K2 & K1 & K2 & K1 & K2 & K1 & K2 \\
\hline Jam ke-1 & 26 & 21 & $\boldsymbol{I}$ & 7 & 0 & 1 & 0 & 0 \\
\hline Jam ke-6 & 29 & 29 & 0 & 0 & 0 & 0 & 0 & 0 \\
\hline Jam ke-24 & 29 & 29 & 0 & 0 & 0 & 0 & 0 & 0 \\
\hline
\end{tabular}


Tabel 4. Perbedaan median nyeri tenggorok jam ke 1, 6 dan 24 antara kelompok Dexametason iv dan Lidokain spray

\section{Median}

\begin{tabular}{cccc}
\hline Waktu(jam) & \multicolumn{3}{c}{$P$} \\
\cline { 2 - 3 } & Dexametason iv & Lidokain spray & \\
\hline $\mathrm{i}$ & 0 & 0 & $0,078^{\mathrm{f}}$ \\
\hline 6 & 0 & 0 & $1,000^{*}$ \\
\hline 24 & 0 & 0 & $1,000^{\epsilon}$ \\
\hline
\end{tabular}

Keterangan : ${ }^{t}$ Mann Whitney test

Sumber: Data Primer

Tabel 5. Perbedaan median suara serak jam ke 1,6 dan 24 antara kelompok

\begin{tabular}{cccc}
\hline Median & $p$ \\
& Dexametason iv & Lidokain spray \\
\cline { 2 - 4 } & 0 & 0 & $0,091^{\text {f }}$ \\
\hline $\mathrm{i}$ & 0 & 0 & $1,000^{*}$ \\
\hline 6 & 0 & 0 & $1,000^{€}$ \\
\hline 24 & & & 0 \\
\hline
\end{tabular}

Keterangan : Mann Whitney test

Sumber : Data Primer 
dan kelompok K2 pasien untuk kelompok yang diberikan lidocain spray pada ETT.

Nilai pada tiap kelompok dalam rerata \pm simpang baku, karakteristik penderita untuk kelompok deksametason intra vena $(\mathrm{K} 1)$ dan lidocain spray $(\mathrm{K} 2)$ terdapat perbedaan tidak bermakna pada usia, berat badan, tinggi badan dan lama operasi.

Kejadian dan derajat nyeri tenggorokan dinilai pada jam ke-1, jam ke-6, dan jam ke-24 setelah ekstubasi. Pada jam ke-1, didapatkan nyeri tenggorok dengan skala nyeri 1 ( ringan ) sebanyak 3 orang pada kelompok 2. Dari analisis statistik didapatkan perbedaan yang tidak bermakna pada kedua kelompok $(P=0,078)$. Pada jam ke 6 dan ke 24 tidak didapatkan nyeri pada kedua kelompok K1 dan K2. Dari analisis statistik tidak didapatkan perbedaan yang bermakna pada kedua kelompok $(P=1,000)$.

Kejadian dan derajat suara serak dinilai pada jam ke-1, jam ke-6, dan jam ke-24 setelah ekstubasi. Pada jam ke-1 didapatkan kejadian suara serak ringan (skala 1) 3 orang pada Kl, dan 7 orang pada K2. Dan didapatkan suara serak sedang ( skala 2) 1 pada K2. Dari analisis statistik didapatkan perbedaan yang tidak bermakna pada kedua kelompok ( $P$ $=0,091$ ). Pada jam ke 6 dan ke 24 tidak didapatkan suara serak pada kedua kelompok K1 dan K2. Dari analisis statistik tidak didapatkan perbedaan yang bermakna pada kedua kelompok $(P=1,000)$.
Nilai perbedaan median nyeri tenggorok pada tiap kelompok penderita untuk kelompok deksametason intra vena (K1) dan lidocain Spray (K2) terdapat perbedaan tidak bermakna pada nyeri tenggorok jam 1 dan tidak terdapat perbedaan pada jam 6, jam 24 pasca operasi.

Nilai perbedaan suara serak pada tiap kelompok penderita untuk kelompok deksametason intra vena $(\mathrm{Kl})$ dan lidocain Jelly (K2) terdapat perbedaan tidak bermakna pada jam ke-1. dan tidak terdapat perbedaan padajam ke-6 dan jam ke-24 pasca operasi.

\section{PEMBAHASAN}

Karakteristik sampel penelitian yang meliputi usia, berat badan, tinggi badan, dan lama operasi ditemukan perbedaan tidak bermakna secara statistik. Sehingga sampel dalam penelitian ini dinilai homogen dan layak untuk dibandingkan. Karena data bersifat homogen, dapat dianggap bahwa variabel yang berpengaruh terhadap skor nyeri pada kedua sampel murni disebabkan oleh perbedaan intervensi yaitu antara pemberian deksametason intravena dan pemberian spray lidokain.

Nyeri tenggorokan setelah operasi merupakan nyeri inflamasi yang terjadi pada $30-70 \%$ pasien dengan intubasi endotrakeal. Terjadi akibat iritasi lokal dan inflamasi pada jalan napas. ${ }^{1}$ Hal ini bisa diakibatkan oleh kontak pipa endotrakea dengan pita suara dan dinding faring atau laring yang mengakibatkan iritasi atau 
trauma pada tonsil, faring, laring atau trakea. $^{2}$

Kortikosteroid memiliki efek antiinflamasi yang luas dengan menghambat semua fase respon inflamasi termasuk pembengkakan, kemerahan, dan sakit serta proliferasi pada inflamasi kronik. Inflamasi ditekan dengan mekanisme yang luas. Pada sirkulasi imunokompeten sel dan makrofag menurun dan formasi mediator proinflamasi termasuk prostaglandin, leukotriens, dan faktor aktivasi thrombosit dihambat. Deksamethason dapat mengurangi sintesis mediator inflamasi, prostaglandin, dan leukotrien dengan menghambat phospholipase A2 dan juga menghambat cyclo-oxygenase selama proses inflamasi. Kerugiannya, steroid IV tidak langsung bekerja dan membutuhkan waktu 3-6 jam untuk memberi efek maksimum, dengan durasi mencapai 48-72 jam. ${ }^{7,8}$

Sebagai obat anestesi lokal, lidokain menstabilisasi membran sel saraf dengan cara mencegah depolarisasi pada membran sel saraf melalui penghambatan masuknva ion natrium. Lidokain bekerja pada penghambatan transmisi (salah satu rangkaian proses nyeri) yaitu proses penyaluran impuls nyeri melalui serabut A delta dan serabut $C$ tak bermielin dari perifer ke medulla spinalis. Apabila reseptornya ditempati maka ion Natrium tidak bisa masuk ke dalam sel. Lidokain menempati reseptornya dan terlepas selama proses perubahan konformasi kanal Natrium. Kanal sel normal yang dihambat li- dokain selama siklus aktivasi - inaktivasi akan cepat terlepas dari reseptornya pada fase istirahat. Sebaliknya kanal yang dalam keadaan depolarisasi kronis yaitu potensial istirahatnya lebih positif, bila diberikan lidokain ( atau penyekat kanal Natrium ) akan pulih lebih lama. ${ }^{9}$

Bila kadar dalam plasma tidak mencapi $9 \mathrm{mcg} / \mathrm{ml}$ maka lidokain dapat ditoleransi dengan baik. Efek samping lidokain yaitu neurotoksik. Gejala yang terjadi dapat berupa kejang, agitasi, disorientasi, euforia, pandangan kabur dan mengantuk. Kejang berlangsung singkat dan berespon dengan pemberian diazepam. ${ }^{9}$

Jam ke-1 paska ekstubasi, didapatkan nyeri tenggorok dengan skala nyeri 1 (ringan) sebanyak 3 orang pada kelompok 2 (spray lidokain), dan tidak didapatkan nyeri pada kelompok 1 (deksametason intravena). Dari analisis statistik didapatkan perbedaan yang tidak bermakna pada kedua kelompok ( $P$ $=0,078$ ). Pada penelitian yang dilakukan Park SH, dkk mengenai penggunaan deksametason sebagai profilaksis nyeri tenggorok dan suara serak setelah ekstubasi pipa endobronkhial double lumen, menunjukkan bahwa kejadian nyeri tenggorok paska ekstubasi dapat dicegah dengan pemberian deksametason 0,2 mg intravena. ${ }^{3}$ Begitu juga Tanaka $\mathrm{Y}$, $\mathrm{dkk}$, telah meneliti penggunaan lidokain untuk mencegah nyeri tenggorok pasca operasi, menyebutkan bahwa lidokain efektif menurunkan kejadian nyeri tenggorok. ${ }^{10}$ 
Suara serak ringan pada jam ke 1 paska ekstubasi ditemukan sebanyak 3 pasien pada kelompok I dan 7 pasien pada kelompok 2. Didapatkan pula suara serak sedang sebanyak 1 pasien pada kelompok 2. Dari analisis statistik didapatkan pebedaan tidak bermakna pada kejadian suara serak jam ke 1 paska ekstubasi ( $P=$ 0,091). Pada jam ke 6 dan jam ke 24 paska ekstubasi tidak didapatkan kejadian suara serak paska ekstubasi. Dari anaiisis statistik tidak didapatkan perbedaan bermakna antara kelompok 1 dan kelompok 2 paska ekstubasi terhadap kejadian suara serak paska ekstubasi $(P=$ 1,000).

Tidak didapatkannya nyeri tenggorok pada jam 6 dan jam 24 paska ekstubasi bisa disebabkan pemberian analgetik yang kuat pada pengelolaan nyeri paska operasi. Analgetik yang diberikan adalah ketorolak $30 \mathrm{mg}$ dan tramadol 2 $\mathrm{mg} / \mathrm{kgBB}$ selama 2 hari paska operasi. Kejadian nyeri dan suara serak yang minimal atau tidak didapatkan sama sekali dapat juga diakibatkan waktu intubasi dilakukan menunggu plika vokalis relaksasi sempurna (exellent), yaitu menunggu hinnga waktu pelumpuh lebih dari waktu onset, dapat juga dipengaruhi oleh bahan pipa endotrakea yang dipakai High Volume Low Pressure, intubasi dilakukan sekali percobaan dalam waktu yang cukup singkat dimana dilakukan oleh residen anestesi tahap akhir di setiap ruang operasi masing-masing.

\section{DAFTAR PUSTAKA}

1. Edomwonyi NP, Ekwere LT, Omo E, Rupasinghe A. Postoperative throat complications after tracheal intubation. Ann Afr Med 2006; 5: 28-32

2. Higgins PP, Chung F, Mezei G. Postoperative sore throat after ambulatory surgery. Br J Anaesth 2002; 88: 582-4

3. Park SH, Han SH, Do SH, Kim JW, Rhee KY, Kim JH. Prophylactic dexamethasone decreases the incidence of sore throat and hoarseness after tracheal extubation with a double-lumen endobronchial tube. Anesth Analg 2008 Dec; 107(6): 1814-8

4. Tabari M, Soltani G, Zirak N, Alipour M, Khazaeni K. Comparison of effectiveness of betamethasone gel applied to the tracheal tube and IV dexamethasone on postoperative sore throat: A Randomized controlled trial. Iran J Otorhinolaryngol 2013; 25(73): 215-20.

5. Honma K, Kamachi M, Akamatsu Y, Yoshioka M, Yamashita N. Lidocaine spray 10 min prior to intubation: Effects on postoperative sore throat. J Anesth 2011 Aug; 25(4): 630

6. Sumathi PA, Shenoy T, Ambareesha M, Krishna HM, Controlled comparison between betamethasone gel and lidocaine jelly applied over tracheal tube to reduce postoperative sore throat, cough and hoarseness of voice. $\mathrm{Br} \mathrm{J}$ Anaesth 2008;100: 215 
7. Neal JM. Medical Pharmacology At A Glance Division Of Pharmacology And Therapeutic $4^{\text {th }}$ Ed. London: Kings College. 2002: 17

8. Pusat Informasi Obat Nasional. Glukokortikoid. Diunduh dari http:// pionas.pom.go.id/book/ioni-bab-6sistem-endokrin-63-kortikosteroid/632glukokortikoid tanggal 12 Desember $\underline{2014}$
9. Muchtar A, Suyatna FD. Obat Antiaritmia. Farmakologi Dan Terapi Edisi 4. Bagian Farmakologi Fakutas Kedokteran Universitas Indonesia. Jakarta: GayaBaru. 1995: 289-314

10. Tanaka Y. Nakayama T, Nishimori M, Sato Y, Furuya H. Lidocaine For Preventing Postoperative Sore Throat. Cochrane Database Syst Rev. 2009 Jul 8; (3) 